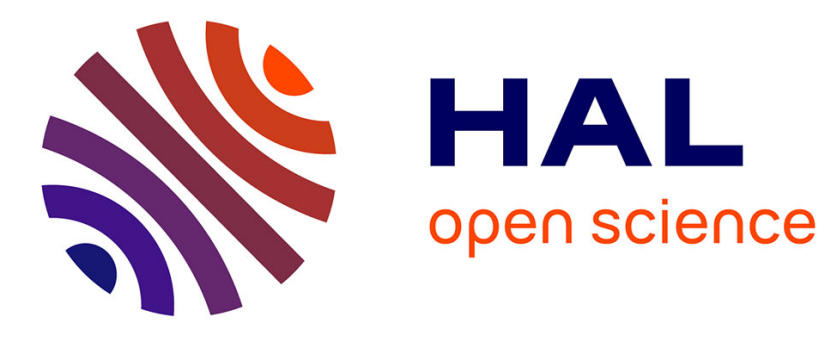

\title{
Oxygen uptake and blood metabolic responses to a 400-m run
}

Christine Hanon, Pierre-Marie Leprêtre, David Bishop, Claire Thomas

\section{To cite this version:}

Christine Hanon, Pierre-Marie Leprêtre, David Bishop, Claire Thomas. Oxygen uptake and blood metabolic responses to a 400-m run. European Journal of Applied Physiology, 2010, 109 (2), pp.233240. 10.1007/s00421-009-1339-4 . hal-01623862

\section{HAL Id: hal-01623862 https://hal-insep.archives-ouvertes.fr/hal-01623862}

Submitted on 30 Oct 2017

HAL is a multi-disciplinary open access archive for the deposit and dissemination of scientific research documents, whether they are published or not. The documents may come from teaching and research institutions in France or abroad, or from public or private research centers.
L'archive ouverte pluridisciplinaire HAL, est destinée au dépôt et à la diffusion de documents scientifiques de niveau recherche, publiés ou non, émanant des établissements d'enseignement et de recherche français ou étrangers, des laboratoires publics ou privés. 


\title{
Oxygen uptake and blood metabolic responses to a 400-m run
}

\author{
Christine Hanon • Pierre-Marie Lepretre • \\ David Bishop $\cdot$ Claire Thomas
}

Accepted: 15 December 2009

(C) Springer-Verlag 2010

\begin{abstract}
This study aimed to investigate the oxygen uptake and metabolic responses during a 400-m run reproducing the pacing strategy used in competition. A portable gas analyser was used to measure the oxygen uptake $\left(\dot{V} \mathrm{O}_{2}\right)$ of ten specifically trained runners racing on an outdoor track. The tests included (1) an incremental test to determine maximal $\dot{V} \mathrm{O}_{2}\left(\dot{V} \mathrm{O}_{2 \max }\right)$ and the velocity associated with $\dot{V} \mathrm{O}_{2 \max }\left(\mathrm{v}-\dot{V} \mathrm{O}_{2 \max }\right)$, (2) a maximal 400 -m (400T) and 3) a 300-m running test (300T) reproducing the exact pacing pattern of the 400T. Blood lactate, bicarbonate concentrations $\left[\mathrm{HCO}_{3}^{-}\right], \mathrm{pH}$ and arterial oxygen saturation were analysed at rest and 1, 4, 7, 10 min after the end of the 400 and 300T. The peak $\dot{V} \mathrm{O}_{2}$ recorded during the $400 \mathrm{~T}$ corresponded to $93.9 \pm 3.9 \%$ of $\dot{V} \mathrm{O}_{2 \max }$ and was reached at $24.4 \pm 3.2 \mathrm{~s}(192 \pm 22 \mathrm{~m})$. A significant decrease in $\dot{V} \mathrm{O}_{2}(P<0.05)$ was observed in all subjects during the last $100 \mathrm{~m}$, although the velocity did not decrease below $\mathrm{v}-\dot{V}_{\mathrm{O}_{2 \max }}$. The $\dot{V} \mathrm{O}_{2}$ in the last $5 \mathrm{~s}$ was correlated with the $\mathrm{pH}(r=0.86, P<0.0005)$ and $\left[\mathrm{HCO}_{3}^{-}\right](r=0.70, P<0.05)$
\end{abstract}

Communicated by Susan Ward.

C. Hanon $(\bowtie) \cdot$ P.-M. Lepretre · C. Thomas Laboratory of Biomechanics and Physiology, French National Institute of Sports (INSEP),

11 Tremblay Avenue, 75012 Paris, France

e-mail: christine.hanon@insep.fr

P.-M. Lepretre

University of Picardie Jules Verne, 80025 Amiens Cedex, France

D. Bishop

Institute of Sport, Exercise and Active Living (ISEAL),

Victoria University, Melbourne, VIC, Australia

C. Thomas

STAPS Department, EA 3872, University of Evry Val

d'Essonne, François Mitterrand Boulevard, 91025 Evry, France measured at the end of 300T. Additionally, the velocity decrease observed in the last $100 \mathrm{~m}$ was inversely correlated with $\left[\mathrm{HCO}_{3}^{-}\right]$and $\mathrm{pH}$ at $300 \mathrm{~T}(r=-0.83, P<0.001$, $r=-0.69, P<0.05$, respectively). These track running data demonstrate that acidosis at $300 \mathrm{~m}$ was related to both the $\dot{V} \mathrm{O}_{2}$ response and the velocity decrease during the final $100 \mathrm{~m}$ of a $400-\mathrm{m}$ run.

Keywords Long sprint running - Buffer capacity · $\mathrm{pH} \cdot$ Bicarbonate

\section{Introduction}

The pacing strategy required for optimal performance in a 400-m running race consists of a fast start followed by an approximate $15 \%$ decrease in velocity, relative to peak velocity, during the last $100 \mathrm{~m}$ of the race (Hanon and Gajer 2009). The adoption of such a fast-start procedure induces a higher peak oxygen uptake $\left(\dot{V} \mathrm{O}_{2 \max }\right)$ compared with other pacing strategies (Bishop et al. 2002; Sandals et al. 2006). While athletes are able to reach their maximal oxygen uptake during a simulated $800-\mathrm{m}$ race (Thomas et al. 2005), previous results have indicated that the peak oxygen uptake reached during a 400-m running race or maximal exercise of equivalent duration $(\approx 1 \mathrm{~min})$ is between 80 and $90 \%$ of $\dot{V} \mathrm{O}_{2 \max }$ (Duffield et al. 2005; Nummela and Rusko 1995; Spencer and Gastin 2001). However, further research is required as these studies did not exactly replicate the competition race conditions (e.g. no start from a starting-block).

In addition to the high aerobic contribution, the anaerobic contribution during a 400-m race is also important and has been reported to range from 57 to $65 \%$ of the total energetic needs during a race (Duffield et al. 2005; Spencer 
and Gastin 2001). The importance of the anaerobic system is reinforced by the strong relationship $(r=0.85$, $P<0.01$ ) between anaerobic glycolysis, as estimated by the maximal lactate levels (above $20 \mathrm{mmol} \mathrm{l}^{-1}$ ), and the average velocity sustained during the $400-\mathrm{m}$ race in highly trained athletes (Lacour et al. 1990). This large anaerobic contribution, and subsequent accumulation of metabolites (Kindermann et al. 1977), may contribute to the decrease in velocity observed during the final $100 \mathrm{~m}$ of a $400-\mathrm{m}$ race (Hanon and Gajer 2009). However, while this decrease in velocity has been reported to occur concomitantly with a decrease in $\dot{V} \mathrm{O}_{2}$ during a 800-m race (Thomas et al. 2005), it is not known if this also occurs during a 400-m race.

Indeed, during 800- and 1,500-m running tests performed according to the pacing strategy of a competition, a decrease in $\dot{V} \mathrm{O}_{2}$ was observed in athletes during a $800-\mathrm{m}$ race (Billat et al. 2009; Thomas et al. 2005) and during a 1,500-m race (Billat et al. 2009; Hanon et al. 2007). Furthermore, there was a significant positive relationship between the decrease in $\dot{V} \mathrm{O}_{2}$ and in velocity during the final stages of both the 800- (Thomas et al. 2005) and 1,500-m running races (Hanon et al. 2007) which suggests that a decrease in velocity may largely be responsible for the decrease in $\dot{V} \mathrm{O}_{2}$. It is important to note however, that the end velocity remained greater than the velocity associated with the $\dot{V} \mathrm{O}_{2 \max }$ of each subject; thus, other mechanisms may also contribute. After maximal exercises, very low muscle and blood pH values (Nielsen 1999), an alteration in muscle buffer capacity (Bishop et al. 2009), and a large decrease in arterial blood bicarbonate concentration to values of $5 \mathrm{mmol} \mathrm{l}^{-1}$ (Kindermann et al. 1977) have been measured. While similar data have not been reported for a competitive $400-\mathrm{m}$ race, it is likely that similar changes occur and that they may contribute to the large velocity decrease in the last $100 \mathrm{~m}$ of a $400-\mathrm{m}$ race, and possibly also to the decrease in $\dot{V} \mathrm{O}_{2}$.

The purpose of this study therefore was to investigate the oxygen uptake response, and the subsequent metabolic and ionic perturbations in the blood, during a 400-m running test (400T) performed according to the optimal competition pace by highly trained $400-\mathrm{m}$ specialists. Due to the pacing strategy (fast start notably) employed in a race (Hanon and Gajer 2009), we hypothesized that athletes would be able to attain a high percentage of $\dot{V} \mathrm{O}_{2 \max }$ and that there would be a $\dot{V} \mathrm{O}_{2}$ decrease during the last $100 \mathrm{~m}$ of the race when the velocity dramatically decreases. Because of the large ionic and metabolic perturbations previously observed at the end of supramaximal exercises (Hirvonen et al. 1992; Kindermann et al. 1977) and their established effects on $\mathrm{O}_{2}$ transport (Nielsen et al. 1999) and utilization (Jubrias et al. 2003), we also hypothesized that the end $\dot{V} \mathrm{O}_{2}$ response might be related to the acid-base status at the intermediate $300-\mathrm{m}$ section of a 400-m running trial.

\section{Methods}

Subjects

Ten 400-m runners (eight men and two women, age $21.8 \pm 4.9$ years, height $1.76 \pm 0.06 \mathrm{~m}$, and body mass $66.3 \pm 6.6 \mathrm{~kg}$ ) volunteered for the study. They trained three to five times per week for the 400-m race and were successful in regional and national running races (average performance of $50.9 \pm 1.2 \mathrm{~s}$ for the men and $57.4 \pm 3.7 \mathrm{~s}$ for the women). The study conformed to the recommendations of the Declaration of Helsinki, and participants gave voluntary written consent to participate in this experiment, which was approved by the local ethics committee.

\section{Experimental protocol}

Subjects performed three track-running tests during the summer competition period, on the same 400-m outdoor track, separated by at least 2 days. The first test was an incremental test aiming to determine $\dot{V} \mathrm{O}_{2 \max }$. This was followed by a $400-\mathrm{m}$ race performed according to the normal competition pacing strategy (400T) and a paced 300-m trial (300T). During this third trial, the subjects were asked to replicate the exact pacing strategy of the previously performed 400T.

For the three tests, oxygen uptake $\left(\dot{V} \mathrm{O}_{2}\right)$, minute ventilation (VE), volume of carbon dioxide released $\left(V \mathrm{CO}_{2}\right)$, respiratory frequency (RF) and tidal volume (VT) were recorded continuously breath-by-breath with a portable gas exchange system (Cosmed $K 4 b^{2}$, Roma, Italy). Calibration of both the Cosmed turbine (3-1 syringe) and gas analysers was performed according to the manufacturer's instructions before each test for each subject. Heart rate (HR) was measured and recorded continuously with a HR monitor (S810i and T61 electrode belt, Polar Electro, Kempele, Finland) for each athlete. Before and after the maximal sessions, arterialized capillary blood samples $(85 \mu \mathrm{l})$ were taken from hyperemized ear-lobes in order to measure blood $\mathrm{pH}$, arterial oxygen saturation $\left(\mathrm{SaO}_{2}\right)$ and bicarbonate concentration $\left(\left[\mathrm{HCO}_{3}^{-}\right]\right)$with an i-STAT dry chemistry analyser (Abbott, Les Ulis, France). These measurements with the i-STAT portable analyser, anaerobically collected (cartridges closed hermetically), have been found to be reliable (ICC $=0.77-0.95$ following maximal exercise) (Dascombe et al. 2007). In order to measure the blood lactate response to exercise, and because of the limited range of the i-STAT system (0.30$\left.20 \mathrm{mmol}^{-1}\right)$, additional samples $(20 \mu \mathrm{l})$ were taken for analysis using a Biosen Lactate analyser (Biosen C-line analyser, EKF Industrie, Elektronik $\mathrm{GmbH}$, Barleben, Germany). 
Incremental running tests

$\dot{V} \mathrm{O}_{2 \max }$ and $\mathrm{v}-\dot{V} \mathrm{O}_{2 \max }$ (minimal speed at which the athlete was running when $\dot{V} \mathrm{O}_{2 \max }$ occurred) were determined using an incremental test conducted on an outdoor track marked every $25 \mathrm{~m}$. The running pace was given by sounds emitted through a speaker controlled by a computer software programme to ensure precise control of speed by setting an audible cadence. The initial velocity was $10 \mathrm{~km} \mathrm{~h}^{-1}$ which was then increased by $1-\mathrm{km}$ every min until exhaustion. Blood samples were taken from the earlobe before and 0 and $3 \mathrm{~min}$ after the end of the test.

Maximal 400-m running test (400T)

The first maximal exercise was a 400-m running test. The warm-up was standardized according to a regular pre-event 400-m warm-up (15 min of jogging, stretching, three successive sprints: $2 \times 50$ - and $1 \times 80-\mathrm{m}$ realized at the 400-m start velocity) and was followed by a 7-min recovery period before the onset of the test. In order to reproduce the competition situation, each athlete used starting-blocks for the start of the race. Athletes were asked to select their own pace in order to realize the best performance and to run as in a competition. After the warm-up, the Cosmed $\mathrm{K} 4 \mathrm{~b}^{2}$ base harness and the HR monitor were put on the participants and the $\mathrm{K} 4 \mathrm{~b}^{2}$ analyser and battery were attached to the runner's torso. The time from the beginning of Cosmed $\mathrm{K} 4 \mathrm{~b}^{2}$ measurement to the start of the time-trial was recorded to locate the exact start in the data files.

\section{Mechanical characteristics}

For each test, athletes were videotaped by a researcher standing on the top of terracing, who used a panoramic video system (Panasonic Super-VHS, sampling rate of $50 \mathrm{~Hz}$ ) from a fixed spot to determine the athlete's velocity at each $25-\mathrm{m}$ interval along the track.

\section{Velocities}

Velocity was calculated by dividing the distance by the time taken to cover this distance. This calculation was performed for each $25 \mathrm{~m}$ in order to provide accurate audio feedbacks on $300 \mathrm{~T}$ and for each $50 \mathrm{~m}$ to calculate stride frequency (SF).

\section{Stride length and frequency}

Stride length (SL) and SF were determined from the video recording (Dart-Fish Team Pro 4.5, Fribourg, Switzerland) between 125 and $175 \mathrm{~m}$ of running for 300- and 400-m run and also between 325 and $375 \mathrm{~m}$ of running for the $400-\mathrm{m}$ run; we avoided the last metres before the finish line where the stride characteristics could be modified. A fatigue index [(peak velocity - final velocity)/peak velocity] $\times 100$ was calculated from the peak and the final velocity being measured over a 25-m distance. SF was calculated from the stride numbers within the $50-\mathrm{m}$ measurement section and from the time between the strides as follows: (number of

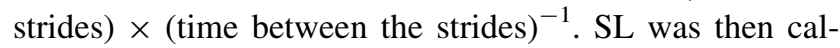
culated as follows: (average velocity) $\times \mathrm{SF}^{-1}$.

Maximal 300-m running test (300T)

The warm-up was conducted as in the previous test but with the $2 \times 50$ - and $1 \times 80$-m sprints performed at the preliminary $400-\mathrm{m}$ start velocity. Athletes were asked to reproduce the identical pacing strategy realized during the previous $400-\mathrm{m}$ running test. To assist the subjects to reproduce an identical pacing regulation, interval times for every $25-\mathrm{m}$ between 0 and $300 \mathrm{~m}$ were determined for each athlete. An audio signal-generator (laboratory self-made) was programmed to produce individualized signals at each 25-m interval. After the warm-up, the $\mathrm{K} 4 \mathrm{~b}^{2}$ system and the heart rate monitor were put on the subjects as described for the 400-m running test.

\section{Blood samples}

Blood samples were taken from the ear lobe just before the start of both the 400 and 300T (that was 4 min after the end of the warm-up) and then at 1, 4, 7 and 10 min during the passive recovery following each test.

\section{Data analysis}

Breath-by-breath gas exchange values were averaged (Cosmed $\mathrm{K}_{4} \mathrm{~b}^{2}$ software) with a 5-s central moving average in order to obtain $\dot{V} \mathrm{O}_{2 \text { max }}$ (incremental test) and $\dot{V} \mathrm{O}_{2 \text { peak }}(400$ and 300T). In order to compare with the literature, the highest incremental 30 -s $\dot{V} \mathrm{O}_{2}$ value $\left(30\right.$-s $\left.\dot{V}_{\mathrm{O}_{2 \max }}\right)$ was also calculated. The end $\dot{V} \mathrm{O}_{2}\left(\dot{V} \mathrm{O}_{2 \text { end }}\right)$ value was defined as the average of the last 5 -s values. The $\dot{V} \mathrm{O}_{2} /$ velocity, expressed in $\mathrm{ml} \mathrm{kg}^{-1} \mathrm{~m}^{-1}$, was calculated for each $25 \mathrm{~m}$ and for each subject.

Statistical analysis

Data are reported as mean $\pm \mathrm{SD}$. The 400T response for gas-exchange variables, HR and running velocity was evaluated by a one-way analysis of variance with repeatedmeasures across each $25-\mathrm{m}$ interval, followed by multiple comparisons (Student-Newman-Keuls) to test the effect of time on the variables. Relationships between variables (running velocity at different times of the race, stride characteristics, metabolic parameters, $\dot{V} \mathrm{O}_{2}$ kinetics and 
final 400-m performance) were analysed by a Pearson's correlation coefficient. All statistical analyses were conducted using Statview software (version 5.0). The level of significance was set at $P<0.05$.

\section{Results}

Incremental test

During this test, $\dot{V} \mathrm{O}_{2 \max }, 30$-s $\dot{V} \mathrm{O}_{2 \max }, \mathrm{v}-\dot{V} \mathrm{O}_{2 \max }$ and the maximal $\mathrm{HR}$ were equal to $60.7 \pm 6.2,59.9 \pm 6.1 \mathrm{ml}$ $\min ^{-1} \mathrm{~kg}^{-1}, 18.3 \pm 1.5 \mathrm{~km} \mathrm{~h}^{-1}$ and $194 \pm 6$ breaths $\min ^{-1}$, respectively. The maximal blood lactate value measured at the end of the test was $10.1 \pm 2.7 \mathrm{mmol} \mathrm{l}^{-1}$.

Performances and velocities during the 400 and $300 \mathrm{~T}$

The mean performance of the 400T was $52.2 \pm 2.4 \mathrm{~s}$ for the men and $60.6 \pm 4.5 \mathrm{~s}$ for the women, and corresponded to $97 \%$ of their best performance. The mean 400 -m velocity was equal to $144.7 \pm 9.8 \%$ of their $\mathrm{v}-\dot{V} \mathrm{O}_{2 \max }$. The peak start velocity (average of the individual distance at which peak start velocity was attained) was reached $67 \pm 22 \mathrm{~m}$ after the onset of the race, and the velocities in the final $100 \mathrm{~m}$ were $8.37 \pm 0.35 \mathrm{~m} \mathrm{~s}^{-1}$ (i.e. $164.2 \% \mathrm{v}-\dot{V} \mathrm{O}_{2 \max }$ ) and $6.93 \pm 0.68 \mathrm{~m} \mathrm{~s}^{-1}$ (i.e. $\left.136.0 \pm 10.5 \% \mathrm{v}-\dot{V} \mathrm{O}_{2 \max }\right)$ for the 300 and $400 \mathrm{~T}$. The intermediary time at $300 \mathrm{~m}$ (I-300) on the 400-m test averaged $39.6 \pm 2.6 \mathrm{~s}$ and was not significantly different from the mean time of the $300-\mathrm{m}$ running test $(300 \mathrm{~T}$ : $40.1 \pm 2.1$ s, i.e. a difference of $1.1 \%$ ). During the $400-\mathrm{m}$ running test, the mean velocity decrease in the last $100 \mathrm{~m}$, expressed as a percentage of the velocity at $300 \mathrm{~m}$, was $9.9 \pm 5.5 \%$ (range from 2.2 to $20.4 \%$ ) and the fatigue index was $22.5 \pm 6.7 \%$, (range from 11.8 to $34.1 \%$ ).

Stride characteristics during the 400-m running test

The mean SL and SF between 125 and $175 \mathrm{~m}$ after the onset of the race was $2.21 \pm 0.11 \mathrm{~m}$ and $3.71 \pm 0.12 \mathrm{~Hz}$, respectively. At the end of the race (between 325 and $375 \mathrm{~m}$ after the onset of the 400T), these values were $1.95 \pm 0.16 \mathrm{~m}$ and $3.52 \pm 0.13 \mathrm{~Hz}$ which corresponded to a significant decrease of $11.5 \pm 3.7$ and $5.1 \pm 3.8 \%$ for the SL and the SF, respectively during $400-\mathrm{m}$ test $(P<0.01)$.

Cardio-respiratory parameters

\section{Oxygen uptake response}

The $\dot{V} \mathrm{O}_{2 \text { peak }}$ reached during the $400 \mathrm{~T}$ was equal to $54.2 \pm 5.7 \mathrm{ml} \mathrm{min}^{-1} \mathrm{~kg}^{-1}$ and was not significantly different $(P>0.05)$ from the values reached during the $300 \mathrm{~T}\left(53.6 \pm 7.6 \mathrm{ml} \mathrm{min} \mathrm{mg}^{-1}\right)$. Figure $1 \mathrm{~b}$ displays the average $\dot{V} \mathrm{O}_{2}$ expressed relative to distance (each point being the average for each $25 \mathrm{~m}$ ). During the 400T, the $\dot{V} \mathrm{O}_{2 \text { peak }}$ value was detected at $192 \pm 21 \mathrm{~m}$ (i.e. $24.4 \pm$ $3.2 \mathrm{~s}$ after the onset of the test). This value corresponded to $93.9 \pm 3.9 \%$ of $\dot{V} \mathrm{O}_{2 \max }$. From $200 \mathrm{~m}$ until the end of the test, a significant decrease in $\dot{V} \mathrm{O}_{2}$ was observed $(P<0.0001)$. In the last $100 \mathrm{~m}$, this significant decrease in $\dot{V} \mathrm{O}_{2}(P<0.05)$ was equal to $8.5 \pm 3.9 \mathrm{ml} \mathrm{min}^{-1} \mathrm{~kg}^{-1}$ $\left(15.6 \pm 6.5 \%\right.$ of $\left.\dot{V} \mathrm{O}_{2 \text { peak }}\right)$ and was observed in all subjects.

\section{$V T, R F, V E$ and $H R$ responses}

The peak values for these variables were observed at 200 (VT), and $275 \mathrm{~m}$ (RF, VE) after the onset of the 400-m running test. These peak values were $1.8 \pm 0.41 \mathrm{~min}^{-1}$, $79.5 \pm 18.9$ breaths $\mathrm{min}^{-1}$ and $128.2 \pm 16.21 \mathrm{~min}^{-1}$ for $\mathrm{VT}, \mathrm{RF}$ and VE, respectively. A significant decrease in these ventilatory variables was noted in the last $100 \mathrm{~m}$ $(P<0.05)$. The HR reached $98.2 \pm 1.7 \%$ of the maximal value $35 \pm 6 \mathrm{~s}$ after the onset of the race and remained constant until the end of the race.

\section{Blood metabolic variables}

The metabolic results measured before and after the running tests are presented in Table 1. The metabolic values, measured post 400T, are significantly different from those measured post 300T except for the $\mathrm{SaO}_{2}$ values which were measured at $1 \mathrm{~min}$. The pre-test values were not significantly different between the tests.

\section{Relationships between ventilatory, biomechanical and metabolic variables}

Table 2 shows that the $400 \mathrm{~T}$ end $\dot{V} \mathrm{O}_{2}$ value was positively correlated with both the $300 \mathrm{~T} \mathrm{pH}$ value $(r=0.85$, $P<0.005)$ (Fig. 2a) and the 300T $\left[\mathrm{HCO}_{3}^{-}\right](r=0.70$, $P<0.05)$. In the same way, the magnitude of the 400T $\dot{V} \mathrm{O}_{2}$ drop was greater when $300 \mathrm{~T}$ lactate concentration was high $(r=0.61, P<0.05)$. On the other hand, the 400T velocity and SL decreases were greater when the $300 \mathrm{~T} \mathrm{pH}$ and $\left[\mathrm{HCO}_{3}^{-}\right]$were low $(P<0.05$ and 0.001 , respectively $)$ (Fig. 2b). The overall time-courses of $\dot{V} \mathrm{O}_{2}$ and velocity were correlated $(r=0.60, P<0.01)$ and this correlation becomes higher $(r=0.92, P<0.0001)$ when considering only the last $200 \mathrm{~m}$. Finally, end $\dot{V} \mathrm{O}_{2}$ values were correlated with both $\dot{V} \mathrm{O}_{2 \text { peak }}(r=0.77, P<0.01)$ and $\dot{V} \mathrm{O}_{2 \max }$ $(r=0.66, P<0.05)$. 

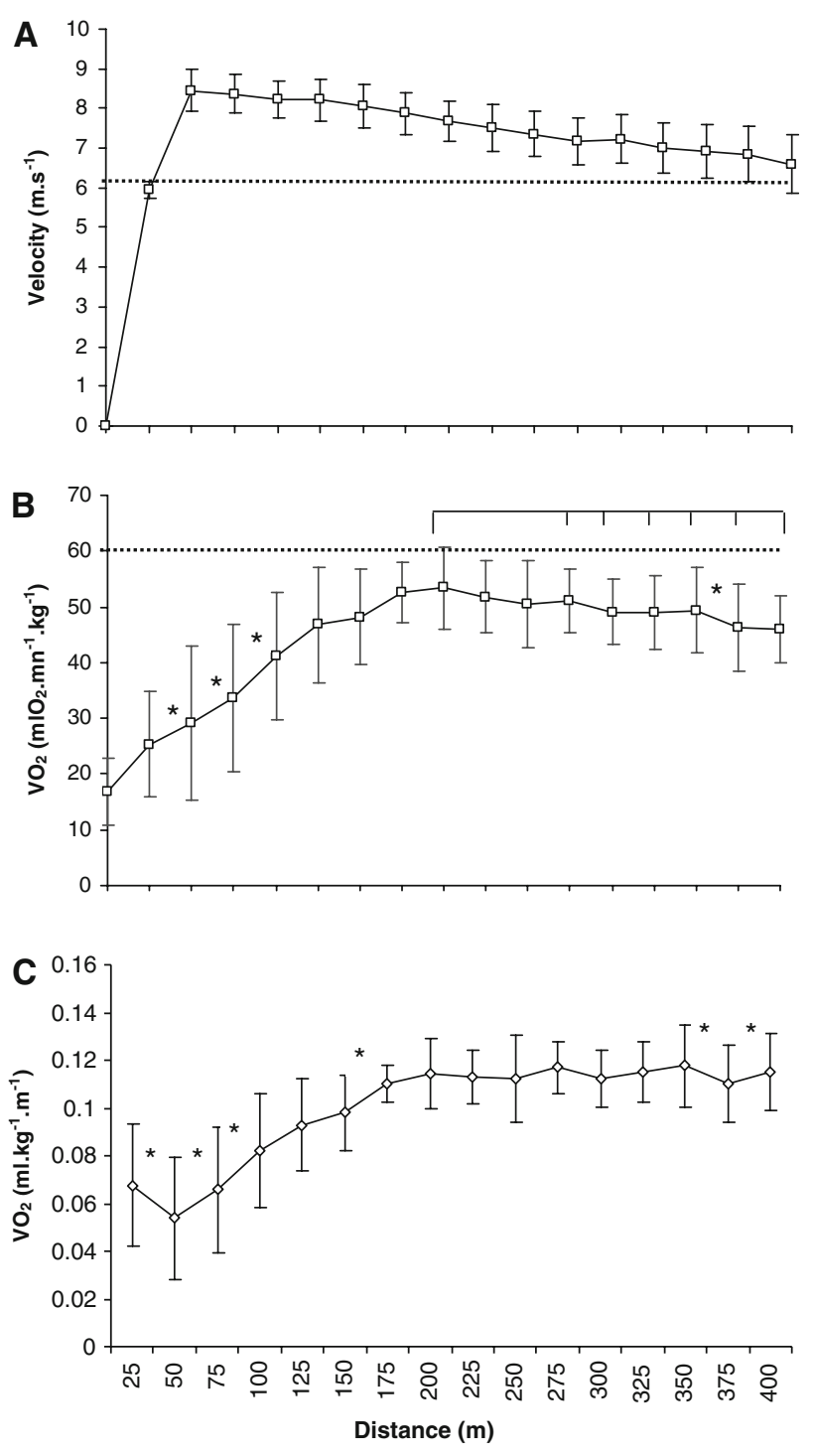

Fig. 1 Time course of a velocity, b oxygen uptake $\mathbf{c}$ oxygen uptake/ velocity during the $400-\mathrm{m}$ running test at each $25-\mathrm{m}$ interval. Values are mean $\pm \mathrm{SD}$; asterisk denotes significant $\dot{V} \mathrm{O}_{2}$ decrease or increase between two consecutive data points, $P<0.05$. Marked area denotes significant decrease relative to $\dot{V} \mathrm{O}_{2 \text { peak }}$. a All differences between two consecutive points are significant excepted between 100-125 and 275-300 m. Broken lines represent the velocity associated with $\dot{V} \mathrm{O}_{2 \max }\left(\right.$ a) or the mean incremental $\dot{V} \mathrm{O}_{2 \max }($ b)

\section{Discussion}

The main finding of the present study was that trained athletes were able to reach a high percentage of $\dot{V} \mathrm{O}_{2 \max }$ in less than $25 \mathrm{~s}$ from the start of a 400-m race. Furthermore, a decrease in $\dot{V} \mathrm{O}_{2}$ corresponding to $15 \%$ of $\dot{V} \mathrm{O}_{2 \text { peak }}$ was observed in the last $100 \mathrm{~m}$ for all subjects. The end $\dot{V} \mathrm{O}_{2}$ and the velocity decrease were positively correlated with both the blood $\mathrm{pH}$ and $\left[\mathrm{HCO}_{3}^{-}\right]$measured after the 300T.

The present study indicated that during a $400-\mathrm{m}$ race well-trained athletes are able to reach $94 \%$ of their $\dot{V} \mathrm{O}_{2 \max }$ in less than $25 \mathrm{~s}$. This $\dot{V} \mathrm{O}_{2 \text { peak }}$ value was higher than that observed in previous field studies where subjects reached 52 (Reis et al. 2004), 82 (Duffield et al. 2005) and 89\% (Spencer and Gastin 2001) of $\dot{V} \mathrm{O}_{2 \max }$ during a 400-m race. To our knowledge, this is the first time that it has been reported that high relative values of $\dot{V} \mathrm{O}_{2 \max }$ can be attained so quickly during running exercise. As reviewed by Gastin (2001), it has previously been demonstrated that $\dot{V} \mathrm{O}_{2}$ can be as high as $90 \%$ of the athlete's maximum after 30-60 s (Gaesser and Poole 1996; Gastin and Lawson 1994; Granier et al. 1995; Poole and Richardson 1997). However, these previous studies all utilized intensive cycling exercise of short duration and with a maximal starting power (Wingate test or all-out exercise). Furthermore, manipulating pacing strategies, previous studies have indicated that $\dot{V} \mathrm{O}_{2}$ during maximal exercise can be increased by employing an all-out start (Bishop et al. 2002; Gardner et al. 2003; Gastin et al. 1995), or a competition-start strategy (Hanon et al. 2008; Thomas et al. 2005). This may be attributable to the greater phosphocreatine (PCr) breakdown at the onset of exercise when using a very fast start procedure (Hirvonen et al. 1992). Similarly, the greater percentage of $\dot{V} \mathrm{O}_{2 \text { peak }}$ values in the present study, compared to previous research may be related to intensive start performed by our trained subjects. A peak velocity as high as $8.37 \mathrm{~m} \mathrm{~s}^{-1}$ (i.e. $164.2 \% \mathrm{v}-\dot{V} \mathrm{O}_{2 \max }$ ), explained by the use of starting-blocks, was reached between 50 and $75 \mathrm{~m}$ after the onset of the race.

Our higher relative $\dot{V} \mathrm{O}_{2 \text { peak }}$ with respect to values observed in previous 400-m studies may also be due to the differences in the $\dot{V} \mathrm{O}_{2}$ sampling window. For example, previous authors (Duffield et al. 2005; Spencer and Gastin 2001) aiming to determine the energy system contributions need not use as small a sampling window as that was used in the present study. As the velocity and therefore the $\mathrm{O}_{2}$ uptake are never steady during a 400-m running race, the use of a large sampling window will tend to smooth and decrease peak values. It can then be concluded that oxygen uptake can attain a level close to the $\dot{V} \mathrm{O}_{2 \max }$ values during brief and intense running exercise, provided that both the start velocity and the duration are sufficient.

In the present study, a $\dot{V} \mathrm{O}_{2}$ decrease was observed during the final $100 \mathrm{~m}$ in all athletes, confirming previous results obtained during other maximal, exhaustive running exercises realized at a constant pace (Nummela and Rusko 1995; Perrey et al. 2002) or in field conditions (Hanon et al. 2007; Thomas et al. 2005). Although undiscussed by the respective authors, this phenomenon also appears in the figures of other studies incorporating paddling or cycling exercise (Bishop et al. 2002; Yamamoto and Kanehsia 1995; Zamparo et al. 1999; Williams et al. 2006). Nevertheless, in previous studies, no decrease has been observed at the end of 400-m running tests. Once more, this could be 
Table 1 Mean \pm SD values for blood parameters measured during the 400- and 300-m running sessions

\begin{tabular}{lllllll}
\hline & & Pre-run & 1 & 4 & 7 & 10 \\
\hline $\mathrm{pH}$ & 300 & $7.40(0.04)^{\mathrm{a}}$ & $7.19(0.05)^{\mathrm{a}, \mathrm{b}}$ & $7.16(0.05)^{\mathrm{a}, \mathrm{b}}$ & $7.18(0.05)^{\mathrm{a}}$ & $7.23(0.05)^{\mathrm{a}, \mathrm{b}}$ \\
& 400 & $7.39(0.04)$ & $7.08(0.04)^{\mathrm{b}}$ & $7.00(0.07)^{\mathrm{b}}$ & $7.00(0.04)$ & $7.00(0.06)$ \\
{$[\mathrm{Lac}]$} & 300 & $3.5(1.2)$ & $14.6(1.5)^{\mathrm{a}, \mathrm{b}}$ & $16.6(1.3)^{\mathrm{a}, \mathrm{b}}$ & $16.8(1.5)^{\mathrm{a}}$ & $15.8(1.9)^{\mathrm{a}}$ \\
& 400 & $3.8(0.8)$ & $16.4(0.9)^{\mathrm{b}}$ & $21.2(2.1)^{\mathrm{b}}$ & $22.0(1.9)$ & $20.0(2.4)$ \\
{$\left[\mathrm{HCO}_{3}^{-}\right]$} & 300 & $20.7(2.3)$ & $13.5(1.9)^{\mathrm{b}}$ & $10.5(1.7)^{\mathrm{a}, \mathrm{b}}$ & $10.0(2.2)^{\mathrm{a}}$ & $10.7(2.2)^{\mathrm{a}, \mathrm{b}}$ \\
& 400 & $19.5(1.4)$ & $9.9(1.2)^{\mathrm{b}}$ & $6.4(1.1)^{\mathrm{b}}$ & $5.5(1.4)^{\mathrm{b}}$ & $4.9(1.3)$ \\
$\mathrm{SaO}_{2}$ & 300 & $97.8(0.4)$ & $96.0(1.6)^{\mathrm{b}}$ & $96.9(1.2)$ & $97.3(0.5)$ & $97.5(1.0)$ \\
& 400 & $97.9(0.3)$ & $95.4(1.0)^{\mathrm{b}}$ & $95.5(1.9)$ & $95.8(1.0)$ & $96.4(1.8)^{\mathrm{b}}$ \\
\hline
\end{tabular}

The blood parameters were collected 3 min before the test at the end of the warm-up (pre-race), and at 1, 4, 7 and 10 min of recovery following both tests. The blood variables are $\mathrm{pH}$, lactate concentration $[\mathrm{Lac}]$ and bicarbonate concentration $\left[\mathrm{HCO}_{3}^{-}\right]$in mmol $1^{-1}$, oxygen saturation $\left(\mathrm{SaO}_{2}\right)$ in $\%$, partial pressure for $\mathrm{O}_{2}\left(\mathrm{PO}_{2}\right)$ and $\mathrm{CO}_{2}\left(\mathrm{PCO}_{2}\right)$ in mmHg. $n=10$ except for [Lac] 400 where $n=8$

${ }^{\text {a }}$ For the same time analysis, 300 data is statistically different from the 400 data (300 pre-race is different from 400 pre-race,..., 300 post 10 is different from 400 post 10$) . P<0.05$

${ }^{\mathrm{b}}$ For the same parameter, statistically different from the previous result (post 4 is different from post $1, \ldots$, post 10 from post 7 ). $P<0.05$

Table 2 Pearson correlation coefficients $(r)$ between the end $\dot{V} \mathrm{O}_{2}$ (last $5 \mathrm{~s}$ ), the velocity decrease (last $100 \mathrm{~m}$ ) measured during the 400T (400-m running test) and the metabolic parameters measured after the 300T (300-m running test)

\begin{tabular}{lccrl}
\hline $300,400 \mathrm{~T}$ & $\mathrm{pH}$ & {$\left[\mathrm{HCO}_{3}^{-}\right]$} & $\mathrm{SaO}_{2}$ & {$[\mathrm{Lac}]$} \\
\hline End $\dot{\mathrm{V}} \mathrm{O}_{2}$ & $0.85^{* *}$ & $0.70^{*}$ & 0.45 & 0.54 \\
$\dot{V} \mathrm{O}_{2}$ decrease $(\%)$ & -0.56 & -0.57 & -0.31 & $0.61^{*}$ \\
Velocity decrease & $-0.69^{*}$ & $-0.83^{* *}$ & -0.29 & 0.52 \\
Stride length decrease & $-0.85^{* *}$ & $-0.68^{*}$ & -0.50 & 0.37 \\
\hline
\end{tabular}

Blood samples taken $4 \mathrm{~min}$ after the end of the $300 \mathrm{~m}$ test except for $\mathrm{SaO}_{2}(1 \mathrm{~min})$

* $P<0.05, * * P<0.01$

explained by the sampling window used by the authors [200 m (Duffield et al. 2005) and $30 \mathrm{~s}$ (James et al. 2007)] which do not allow this observation during such intense and brief exercise. Nummela and Rusko (1995) who observed a $\dot{V} \mathrm{O}_{2}$ decrease at the end of a maximal 50-s treadmill exercise used a 5-s sampling window.

In the present study, this decrease in $\dot{V} \mathrm{O}_{2}$ appeared to be related to the peak [lactate]. The peak blood lactate concentration measured in the present study $(22.0 \pm$ $1.9 \mathrm{mmol}^{-1}$ ), which was similar to values traditionally observed after a competitive 400-m race (Kindermann et al. 1977; Lacour et al. 1990), but was higher than all recent experimental data on 400-m races (Duffield et al. 2005; Reis et al. 2004) ( $\approx 13$ to $16 \mathrm{mmol}^{-1}$ ); these differences may have contributed to the absence/presence of this phenomenon. In the last $100 \mathrm{~m}$, additional significant decreases in $\mathrm{pH}$ (7.18 to 7.00$)$ and $\left[\mathrm{HCO}_{3}^{-}\right]\left(10.7\right.$ to $\left.4.9 \mathrm{mmol} \mathrm{l}^{-1}\right)$ were observed, and the $\mathrm{pH}$ and $\left[\mathrm{HCO}_{3}^{-}\right]$values measured at the onset of the $\dot{V} \mathrm{O}_{2}$ decrease $(300 \mathrm{~m})$ were significantly related to the $400 \mathrm{~T}$ end $\dot{V} \mathrm{O}_{2}$ values. This final metabolic state aggravation, observed at the end of the 400T, is in accordance with the depletion revealed in blood bicarbonate after competitive rowing (Nielsen 1999), as well as the decrease in muscle buffering capacity observed after $45 \mathrm{~s}$ of exhausting exercise (Bishop et al. 2007), with the result being that the organism is unable to prevent an additional acidosis. Then, the decrease in $\dot{V} \mathrm{O}_{2}$ and in velocity could be related to acidosis-induced inhibition of oxidative phosphorylation in contracting muscles (Jubrias et al. 2003) and consequently, with the large decrease in ATP observed at the end of a 400-m race (Hirvonen et al. 1992). It should be noted however, that the decrease in $\dot{V} \mathrm{O}_{2}$ observed in the present study was not correlated to the $\mathrm{pH}$ values at $300-\mathrm{m}$ ( $r=-0.56, P=0.10$ ). Furthermore, the correlations observed between end $\dot{V} \mathrm{O}_{2}$ and both $\dot{V} \mathrm{O}_{2 \text { peak }}$ and $\dot{V} \mathrm{O}_{2 \max }$ could indicate that athletes with a high $\dot{V} \mathrm{O}_{2 \max }$ (and therefore high end $\dot{V} \mathrm{O}_{2}$ ) may have presented higher $\mathrm{pH}$ values at $300 \mathrm{~m}$ due to a greater use of aerobic energy resources during the $400 \mathrm{~m}$ test than athletes with a lower $\dot{V} \mathrm{O}_{2 \max }$.

Blood metabolic perturbations, which could reflect changes in the muscle, could contribute to greater muscle fatigue during the last $100 \mathrm{~m}$ since the velocity strongly decreased (SL in particular) until values above the velocity associated with $\dot{V} \mathrm{O}_{2 \max }$ in each athletes. This velocity drop was negatively and significantly correlated to blood $\mathrm{pH}$ post 300T and to the $\left[\mathrm{HCO}_{3}^{-}\right]$. The progressive reduction in running speed could then be the result of a combination of changes occurring in the muscle resulting in an incapacity to compensate for fatigue (Nummela et al. 1992). The significant correlation between the metabolic values at $300 \mathrm{~m}$ (blood $\mathrm{pH}$ and $\left[\mathrm{HCO}_{3}^{-}\right]$) and the subsequent velocity decrease suggests that the ability of the athletes to finish strongly during this type of exhausting exercise may be linked to the level of acidosis when approaching the finish line. 

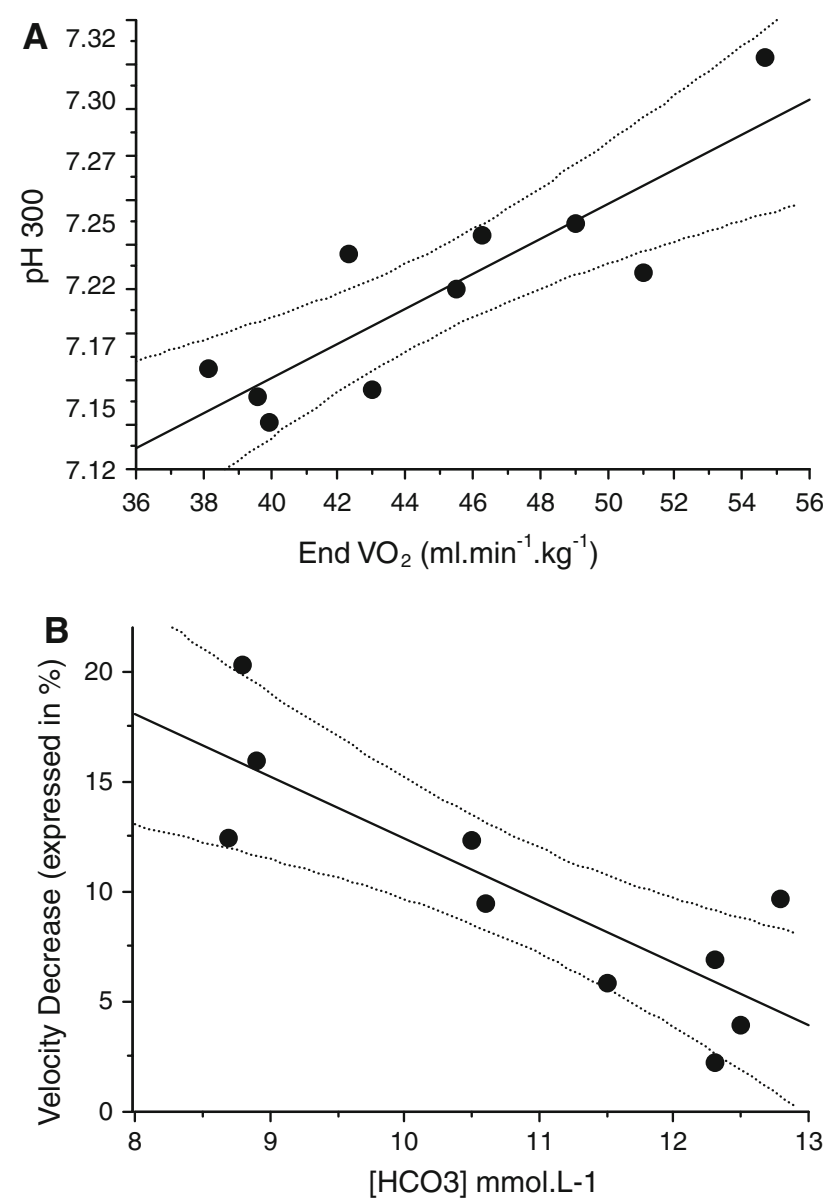

Fig. 2 a Relationship between the 400-m end velocity (last $100 \mathrm{~m}$ expressed in $\%$ of the velocity at $300 \mathrm{~m})$ and the $\left[\mathrm{HCO}_{3}^{-}\right]$values measured $4 \mathrm{~min}$ after the 300T. $n=10, R=-0.83, P<0.001$. b Relationship between the $400-\mathrm{m}$ end $\dot{V} \mathrm{O}_{2}$ (last $5 \mathrm{~s}$ ) and blood $\mathrm{pH}$ values measured 4 min after the 300T. $n=10, R=0.86, P<0.001$. The broken lines indicate the $95 \%$ confidence intervals

Dempsey et al. (1982) have also demonstrated that physiological perturbations in the $\mathrm{O}_{2}$ transport system, such as ventilatory regulation, could be induced by metabolic $\mathrm{H}^{+}$accumulation. Indeed, during the 400-m race, our subjects presented particularly extreme peak values of RF $\left(81 \pm 22\right.$ breaths $\left.\mathrm{min}^{-1}\right)$. These results could indicate that our subjects hyperventilated in order to partially compensate for their metabolic acidosis and to maintain an effective alveolar $\mathrm{O}_{2}$ partial pressure (Miyachi and Katayama 1999) since VE continued to raise whereas $\dot{V} \mathrm{O}_{2 \text { peak }}$ had already been reached (Dempsey et al. 1982). Furthermore, a development of fatigue in respiratory muscles has been demonstrated during exhausting exercise (Gallagher et al. 1985), and a decrease in VT, which could indicate a reduction of inspiratory muscles strength, has been reported in the present study and in studies which observed a decrease in oxygen uptake (Billat et al. 2009; Hanon et al. 2007; Perrey et al. 2002; Thomas et al. 2005). During maximal whole-body exercise, the combination of a very low $\mathrm{pH}$ value and a poor vital capacity (unverified in this study, but demonstrated by Nielsen- et al. 1999) becomes critical for arterial oxygen pressure $\left(\mathrm{PaO}_{2}\right)$ and consequently for $\dot{V} \mathrm{O}_{2}$ (Dempsey et al. 1982). In the present study however, no significant relationship was observed between the magnitude of the $\dot{V} \mathrm{O}_{2}$ decrease and the recovery $\mathrm{SaO}_{2}$ values. Nevertheless, a $\mathrm{SaO}_{2}$ value of $95 \%$ measured $1 \mathrm{~min}$ after the end of the trial has been reported to correspond to a final $\mathrm{SaO}_{2}$ value of less than $90 \%$ (Rasmussen et al. 1991). Therefore, the relation between end $\dot{V} \mathrm{O}_{2}$ and $\mathrm{SaO}_{2}$ needs to be more accurately tested.

The time-courses of $\dot{V} \mathrm{O}_{2}$ and velocity have been shown to be highly correlated in the last $200 \mathrm{~m}$ and both the velocity decrease and the end $\dot{V} \mathrm{O}_{2}$ observed during $400 \mathrm{~T}$ have been shown to be related to the acidosis measured at $300 \mathrm{~m}$. We can then, therefore, hypothesize that a common mechanism may explain the decrease in both $\dot{V} \mathrm{O}_{2}$ and velocity. However, the question remains: does the $\dot{V} \mathrm{O}_{2}$ decrease the consequence or the cause of the velocity decrease? It is also possible that both are the result of the metabolic perturbations and unrelated to each other.

A possible implication of this study for training is that improving the capacity of the buffer systems and the aerobic power may result in a smaller decrease in both $\mathrm{pH}$ and velocity at the end of the race. This advantage should be obtained without decreasing the capacity of the athlete to run very fast in the first $300 \mathrm{~m}$. However, the absence of muscle data and the delay between the end of the exercise and $\mathrm{SaO}_{2}$ measurement have to be considered as limitations in the interpretation of our results.

\section{Conclusion}

These track-running data demonstrate that a highly relative $\dot{V} \mathrm{O}_{2}$ can be reached within $25 \mathrm{~s}$ from the start of a $400-\mathrm{m}$ trial and that the end $\dot{V} \mathrm{O}_{2}$ values may be the consequence of metabolic perturbations correlated to the acidosis. The accurate physiological hypotheses explaining the $\dot{V} \mathrm{O}_{2}$ decrease during a maximal running exercise performed above the velocity associated to $\dot{V} \mathrm{O}_{2 \max }$ need to be specifically investigated in order to demonstrate the central or (and) peripheral cause of this phenomenon.

Acknowledgement The authors are grateful to the French Ministry of Health, Youth and Sport for their financial support and to B. Reine (INSEP) for his technical assistance.

\section{References}

Billat V, Hamard L, Koralsztein JP, Morton RH (2009) Differential modeling of anaerobic and aerobic metabolism in the 800-m and 1, 500-m run. J Appl Physiol 107:478-487 
Bishop D, Bonetti D, Dawson B (2002) The influence of pacing strategy on VO2 and supramaximal kayak performance. Med Sci Sports Exerc 34:1041-1047

Bishop D, Edge J, Thomas C, Mercier J (2007) High-intensity exercise acutely decreases the membrane content of MCT1 and MCT4 and buffer capacity in human skeletal muscle. J Appl Physiol 102:616-621

Bishop D, Edge J, Mendez-Villanueva A, Thomas C, Schneiker K (2009) High-intensity exercise decreases muscle buffer capacity via a decrease in protein buffering in human skeletal muscle. Pflugers Arch 458:929-936

Dascombe BJ, Reaburn PR, Sirotic AC, Coutts AJ (2007) The reliability of the i-STAT clinical portable analyser. J Sci Med Sport 10:135-140

Dempsey J, Hanson P, Pegelow D, Claremont A, Rankin J (1982) Limitations to exercise capacity and endurance: pulmonary system. Can J Appl Sport Sci 7:4-13

Duffield R, Dawson B, Goodman C (2005) Energy system contribution to 400-metre and 800-metre track running. J Sports Sci 23:299-307

Gaesser GA, Poole DC (1996) The slow component of oxygen uptake kinetics in humans. Exerc Sport Sci Rev 24:35-71

Gallagher CG, Im Hof V, Younes M (1985) Effect of inspiratory muscle fatigue on breathing pattern. J Appl Physiol 59:11521158

Gardner A, Osborne M, d'Auria S, Jenkins DG (2003) A comparison of two methods for the calculation of accumulated oxygen deficit. J Sports Sci 21:151-162

Gastin PB (2001) Energy system interaction and relative contribution during maximal exercise. Sports Med 31(10):725-741

Gastin PB, Lawson DL (1994) Influence of training status on maximal accumulated oxygen deficit during all-out cycle exercise. Eur J Appl Physiol 69:321-330

Gastin PB, Costill DL, Lawson DL, Krzeminski K, McConell GK (1995) Accumulated oxygen deficit during supramaximal all-out and constant intensity exercise. Med Sci Sports Exerc 27:255263

Granier P, Mercier B, Mercier J, Anselme F, Préfaut C (1995) Aerobic and anaerobic contribution to Wingate test performance in sprint and middle-distance runners. Eur J Appl Physiol 70:58-65

Hanon C, Gajer B (2009) Velocity and stride parameters of worldclass 400-meter athletes compared with less experienced runners. J Strength Cond Res 23(2):524-531

Hanon C, Leveque JM, Vivier L, Thomas C (2007) Time course of velocity and oxygen uptake during $1500-\mathrm{m}$ realized with a strategy of best chronometric performance. N Stud Athl 22:115122

Hanon C, Leveque JM, Thomas C, Vivier L (2008) Pacing strategy and $\mathrm{VO}_{2}$ kinetics during a $1500-\mathrm{m}$ race. Int $\mathrm{J}$ Sports Med 29:206-211

Hirvonen J, Nummela A, Rusko H, Rehunen S, Harkonen M (1992) Fatigue and changes of ATP, creatine phosphate, and lactate during the 400-m sprint. Can J Sport Sci 17:141-144

James DVB, Sandals LE, Draper SB, Wood DM (2007) Relationship between maximal oxygen uptake and oxygen uptake attained during treadmill middle-distance running. J Sports Sci 25:851858

Jubrias SA, Crowther GJ, Shankland EG, Gronka RK, Conley KE (2003) Acidosis inhibits oxidative phosphorylation in contracting human skeletal muscle in vivo. J Physiol 553:589-599

Kindermann W, Keul J, Huber G (1977) Physical exercise after induced alkalosis (bicarbonate or tris-buffer). Eur J Appl Physiol 37:197-204

Lacour JR, Bouvat E, Barthélémy JC (1990) Post-competition blood lactate concentrations as indicators of anaerobic energy expenditure during 400-m and 800-m races. Eur J Appl Physiol 61:172-176

Miyachi M, Katayama K (1999) Effects of maximal interval training on arterial oxygen desaturation and ventilation during heavy exercise. Jpn J Physiol 49:401-407

Nielsen HB (1999) pH after competitive rowing: the lower physiological range? Acta Physiol Scand 165:113-114

Nielsen HB, Boushel R, Madsen P, Secher NH (1999) Cerebral desaturation during exercise reversed by $\mathrm{O}_{2}$ supplementation. Am J Physiol 277:H1045-H1052

Nummela A, Rusko H (1995) Time course of anaerobic and aerobic energy expenditure during short-term exhaustive running in athletes. Int J Sports Med 16:522-527

Nummela A, Vuorimaa T, Rusko H (1992) Changes in force production, blood lactate and EMG activity in the 400-m sprint. J Sports Sci 10:217-228

Perrey S, Candau R, Millet GY, Borrani F, Rouillon JD (2002) Decrease in oxygen uptake at the end of a high-intensity submaximal running in humans. Int J Sports Med 23:298-304

Poole DC, Richardson RS (1997) Determinants of oxygen uptake. Implications for exercise testing. Sports Med 24:308-320

Rasmussen J, Hanel B, Diamant B, Secher NH (1991) Muscle mass effect on arterial desaturation after maximal exercise. Med Sci Sports Exerc 23:1349-1352

Reis VM, Duarte JA, Espirto-Santo J, Russel AP (2004) Determination of accumulated oxygen deficit during a 400-m run. J Exerc Physiol Online 7:77-83

Sandals LE, Wood DM, Draper SB, James DV (2006) Influence of pacing strategy on oxygen uptake during treadmill middledistance running. Int J Sports Med 27:37-42

Spencer MR, Gastin PB (2001) Energy system contribution during $200-$ to $1500-\mathrm{m}$ running in highly trained athletes. Med Sci Sports Exerc 33:157-162

Thomas C, Hanon C, Perrey S, Le Chevalier JM, Couturier A, Vandewalle H (2005) Oxygen uptake response to an 800-m running race. Int J Sports Med 26:268-273

Williams CA, Doust JH, Hammond A (2006) Power output and $\mathrm{VO}_{2}$ responses during $30 \mathrm{~s}$ maximal isokinetic cycle sprints at different cadences in comparison to the Wingate test. IES 327333

Yamamoto M, Kanehsia H (1995) Dynamics of anaerobic and aerobic energy supplies during sustained high intensity exercise on cycle ergometer. Eur J Appl Physiol 71:320-325

Zamparo P, Capelli C, Guerrini G (1999) Energetics of kayaking at submaximal and maximal speeds. Eur J Appl Physiol 80:542548 